\title{
Evolution of Research on Elite Adult Athlete Sleep: A Systematic Review
}

\author{
Aldo C. Silva ${ }^{1,2 *}$, Lucas A. Facundo ${ }^{1}$, Adriana S. Amaral', Diego A. Borba ${ }^{1}$, João P. P. Rosa ${ }^{1}$, Andressa \\ Silva ${ }^{1}$ and Marco T. de Mello ${ }^{1}$ \\ ${ }^{1}$ Universidade Federal de Minas Gerais, Belo Horizonte/Brazil \\ ${ }^{2}$ Faculdade Claretiano, Belo Horizonte/Brazil
}

*Corresponding author: Aldo Coelho Silva, PhD, Faculdade Claretiano, rua dos Aimorés, 1583, Lourdes, CEP: 30140-071, Belo Horizonte, MG, Brazil, Tel: 55-31-999051985

\begin{abstract}
To describe the evolution of research on elite adult athlete sleep. A systematic literature review was performed in PubMed, Web of Science, Scopus, and Sport Discus databases. Studies where sleep was the main variable and included only elite (national or international level), healthy (no injury or any pathology), and adult athletes were included for analysis. Only articles published in the English language were considered. After analyzing all inclusion and exclusion criteria, 50 studies were included. A continental disparity in publications was observed, with a concentration of studies in Oceania and Europe. A total of 2964 athletes were observed, mostly men, and the most studied modality was soccer. As of 2015, actigraphy became the most used method to monitor sleep in athletes, followed by questionnaires and sleep diaries. At no other historical moment has the sleep of the elite adult athlete been so inserted in the scientific area. Elite adult athlete sleep research is an expanding area in sports science and factors such as the elite athlete's gender and modality, as well as the publication's instruments and geographic location, will contribute to filling the knowledge gaps in this theme.
\end{abstract}

\section{Keywords}

Sleep, Performance, Training, Competition

\section{Introduction}

Sleep is considered important for body restoration resulting from the waking period, with a restorative and repairing process in fatigue and energy [1]. For the athlete, sleep is essential for both training, and competition. There is also the fact that sleep provides optimal cognitive activities and decision-making capacity, contributing to an optimal mental state for the athlete [2,3]. The American Sleep Foundation recommends that most healthy adult achieve between 7 to 9 hours of sleep per night, with some variation by age group [4]. While there is no consensus on the optimal amount of sleep per night for athletes, it has been suggested that athletes get the optimal amount of sleep to feel up and alert for the next day [5].

Despite this concern and the recognized importance of sleep [6,7], evidence indicates that athletes can be subjected to stressful situations that compromise the quality and quantity of sleep, such as training, competition, and travel. Especially elite athletes may suffer more from these changes, considering that they are in constant travel and under training and competition throughout the sports season $[8,9]$. When it comes to travel, elite athletes constantly cross multiple time zones, participating in training and competitions in environments far from their homes. Due to the high physiological and psychological demands, readjusting to the new time zone and the new climate can negatively affect the athlete's sleep [10].

Recently, Lastella, Memon [11] performed a bibliometric analysis of sleep surveys in athletes. The authors identified that the first study on athlete sleep took place in 1966 and observed that the last decade (2010-2019) was responsible for a substantial increase in the number of publications in the area. On the other hand, 
the use of the term athlete without a definition makes the number of studies in the area comprehensive, which hinders the understanding and practical use of research in the field of sports science about the athlete. Araujo and Scharhag [12] suggest a series of criteria for a subject to be considered an athlete, in addition to the presentation of information such as age group (young, adult or master) and performance level (beginner, national, world, and Olympic) in the characterization Sample. Athletes are often described as recreational, leisure, amateur, novice, competitive, non-professional, professional, experienced, national level, high level, Olympic, best level, top-level, and elite. Recently, Swann, Moran [13] in an attempt to structure the information in the scientific community related to the characterization of the elite/expert athlete, proposed a taxonomy to classify this athlete's level, considering factors such as performance, success, high-level experience, competitiveness sport of the sport in the athlete's country and the global competitiveness of the sport. In this sense, it is observed that research in the field of sports science should be concerned with describing with precise information the characteristics of the observed athlete.

Thus, the lack of definition and specificity in the description of the athlete can lead to difficulties in replicating and comparing studies $[12,14]$, in addition to hindering the understanding of research related to sport. Therefore, this article aimed to present the evolution of the literature in studies on the sleep of the elite adult athlete, through a systematic review. The geographic location, modalities, and the instruments used of the studies were addressed. The observed gaps and suggestions for future studies are also presented.

\section{Materials and Methods}

\section{Search strategies}

The systematic literature review was carried out by two researchers from the electronic databases PubMed, Web of Science, Scopus, Sport Discus, and Virtual Health Library. The first two databases were searched by Endnote X7 (Thomas Reuters, USA) and the other databases were searched on their websites in February 2020. The search terms were searched in "any field", in all the databases. The terms used were sleep AND athlet ${ }^{*}$ and its terms Medical Subject Headings (MeSH).

The search in the databases had no temporal limitation and was updated in June 2021. There was a limitation for original articles that had been studied with human beings and written in the English language. This review was based on the PRISMA (Preferred Reporting Items for Systematic Reviews and Meta-Analyses) model, which consists of a 27-item checklist and a fourphase flow diagram [15].

\section{Eligibility criteria}

For inclusion, the study should use elite adult athletes (mean over 18-years-old); the main variable (dependent or independent) should be sleep; only healthy athletes (without injury or any pathology). For this review, "elite" was considered participation in national or international sporting events $[16,17]$. Furthermore, if the athlete were described as a professional, without the exact level of performance, the study would be excluded. There were not added university athletes. Paralympic or adapted sports athletes were not considered. Review, systematic or critical, short-communication, and editorial articles were excluded, as well as studies to be published (ahead of print). Studies were excluded if they did not meet at least one selection criteria, as well as articles that performed sleep deprivation or restriction protocols. When some information was not fully described, we emailed the authors. If our doubt was not answered, the article was not included. Screening and data extraction were performed by two researchers. Disagreements on any article or outcome were discussed among the authors and resolved by additional authors when necessary.

\section{Selection of studies}

After removing the duplicate articles, the reading of the titles and abstract were performed by an author (ACS). Next, two authors examined the articles in full (ACS, ASA) to confirm the inclusion and eligibility criteria. If there was a disagreement between the eligible articles, a third author would be invited (LAF). After this procedure of selecting eligible articles, they were tabulated by an author (ACS), extracting information from the study design, participants, and results/outcomes.

\section{Classification of study design}

Articles were categorized as descriptive or experimental. Descriptive articles were studies in which researchers established a relationship between variables or characterized the sleep of athletes, quantitatively or qualitatively [18]. Experimental articles were studies that tested hypotheses with interventions, volunteers were divided into at least two conditions or two groups and there was a comparison of the intervention in sleep.

\section{Study type classification}

Articles were classified as longitudinal or crosssectional. Articles were classified into longitudinal if sleep was monitored repeatedly or continuously over a while in the same athlete [19], for this study the minimum time was one week. Articles in which the data collection period was at a specific point in time were classified as cross-sectional [20].

\section{Classification of the instrument}

The instruments used were classified into five groups: Polysomnography, with monitoring of electrical activities in the brain; actigraphy, with analysis of the 
sleep-wake cycle through an accelerometer; sleep diary, subjective description with structured information; questionnaires, instruments to describe aspects of sleep; and non-specific objective instruments (Others).

\section{Results}

A total of 3753 articles were found, with 782 in the PubMed database, 909 in the Web of Science, 807 in Scopus, 732 in Sport Discus, and 523 in the Virtual Health Library. After the first analysis regarding the duplicity of articles and articles titles, 134 articles remained. After reading the titles and abstracts, 12 articles were excluded for not being part of the eligibility criteria (for example articles in non-English language) and 122 articles remained. A second reviewer also read the titles, abstracts, and text in full. With the full reading of the selected articles, 74 articles were excluded (for example articles that did not use elite adult athletes) and another 4 articles were identified with potential for inclusion. Following the reading of the titles and abstracts of potential articles, 2 articles were included. Then, 50 articles were included for the final review (Figure 1). No unpublished articles have been added.

The temporal distribution of publications, the cumulative number of publications, and the percentage of publications per year are shown in Figure 2 . The articles
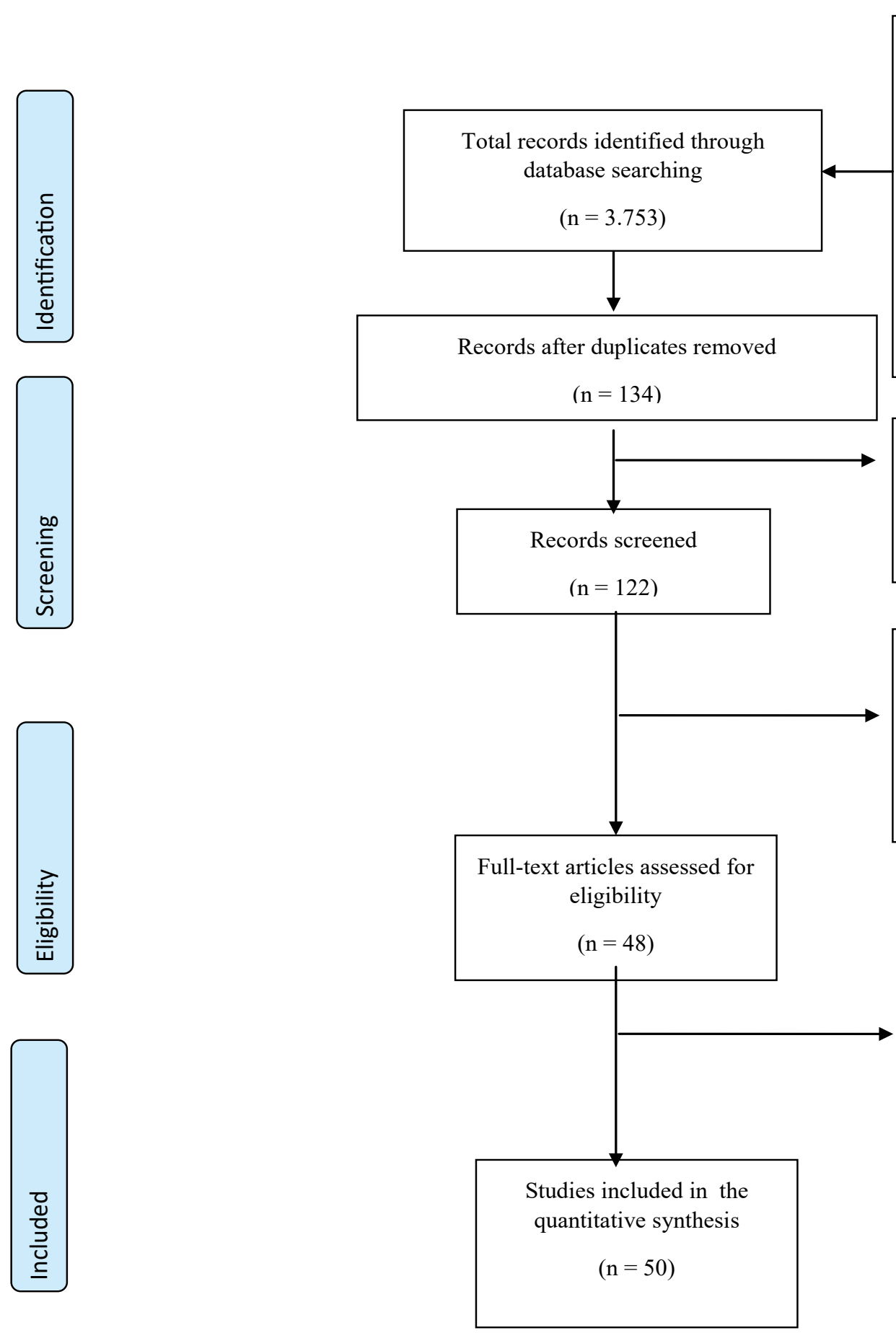

Searched databases (number of identified records)

Pubmed $(\mathrm{n}=782)$

Web of science $(n=909)$

Scopus $(\mathrm{n}=807)$

SPORTDiscus $(\mathrm{n}=732)$

Virtual Healthy Library $(\mathrm{n}=$ 523)

Records excluded $(\mathrm{n}=12)$

Not English

Full-text articles excluded $(\mathrm{n}=$ 74) with reasons:

Not met the inclusion criterio $=$ 69

Not English $=5$

Additional records through forward searching (of potentially relevant records)

$$
(\mathrm{n}=2)
$$

Figure 1: Flow chart. 


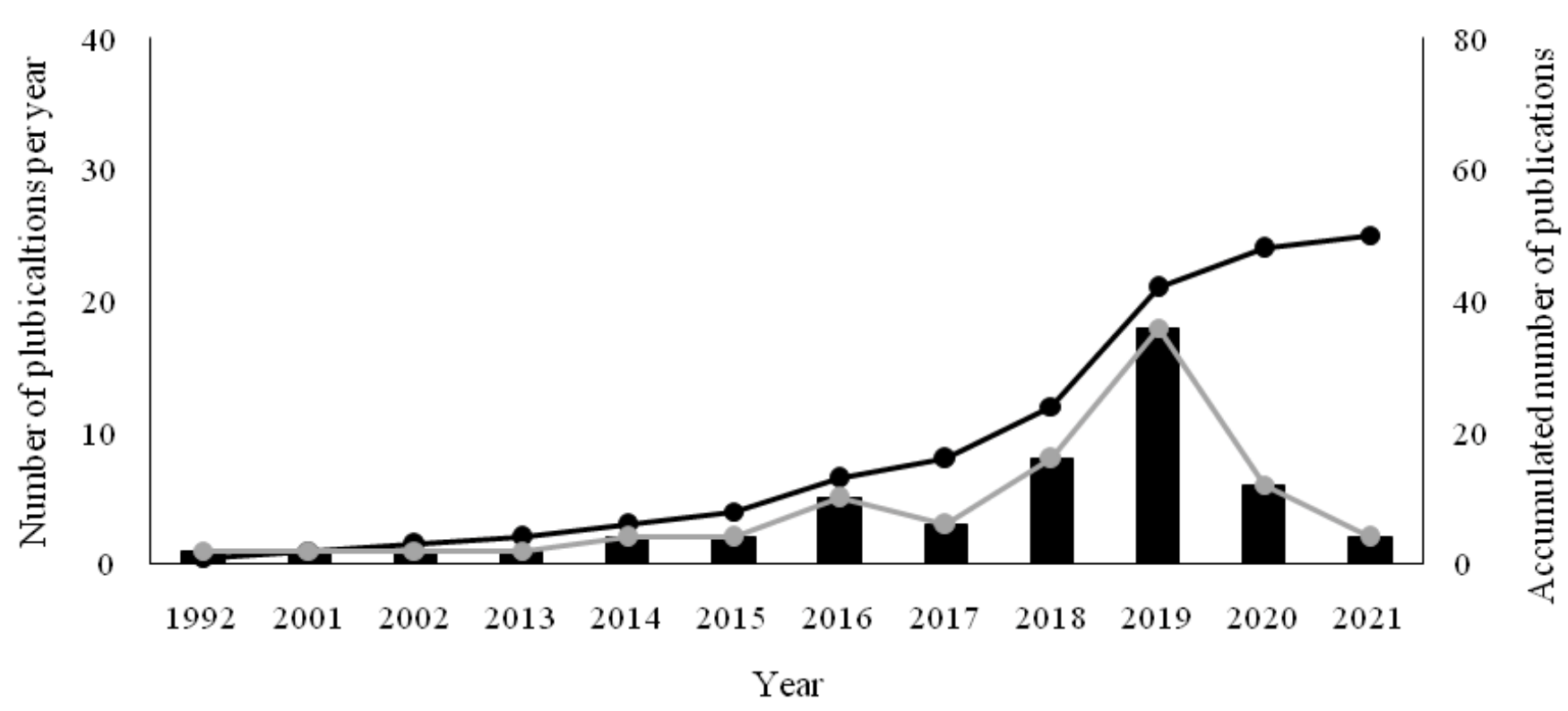

$\rightarrow$ Cumulative number of publications

Number of publications per year

Percentage of publications

Figure 2: Temporal distribution of articles on athlete's sleep (1992-2021).

were published between 1992 and 2021 [2,21-69]. Throughout the 1990s, only one article was published, and in the following decade, two more articles were published $[63,64]$. In the last decade, there has been a significant increase in publications $[2,21,23,24,26,27,30-$ $32,35-39,41,42,44-62,66-69]$, representing almost $80 \%$ of the number of publications throughout the period. The years 2018 and 2019 were the two years with the highest number of publications, representing more than $50 \%$ of the articles published.

Table 1 of the supplementary material presents the 50 studies with the information: First author, year of publication, place of data collection, sample, performance level, and the instrument used to monitor sleep. There was a great continental disparity, with Oceania [2,24,25,30,32,35-39,47,49-62,67], responsible for more than $50 \%$ of the articles. Brazil $[22,23,28,29,46]$, Japan $[33,45,69]$ and Portugal $[41-43,48]$ were the countries with more publications in America, Asia, and Europe, respectively. There was no publication from the African continent.

The minimum sample quantity was seven athletes [30,52] and the maximum was 817 athletes [45]. A total of 2964 athletes was observed, with 1068 female athletes. The sample was composed only of women in $14 \%$ of the articles $[2,41,42,48,51,55,66]$, while in $60 \%$ of the articles the sample was composed exclusively of men [22,24-28,30-32,34-40,43,47,50,54,56-61,63$65,67]$. In $40 \%$ of the articles the sample was composed only of athletes with international performance $[2,23,26-30,32,33,38,40,45,46,49,59,63,65,66,68,69]$ and in $4 \%$ of the articles the sample was composed with of athletes with national and international performance [39,52,61,62]. Fifty-six sports modalities were present in the articles. The team sport and individual sport most observed were soccer [22,27,28,30$32,41,42,45,48,49,57,62,63,66,67,69]$ and swimming $[23,29,45,46,52,53,69]$, respectively.

Regarding the type of study (Figure $3), 30 \%$ of the articles were experimental $[28,29,33,34,36,38,44,46,57,59,61,63,65-67]$. With regard to study time, $42 \%$ of the articles were longitudinal $[22,25,26,30,32,34,35,38-44,52-55,57,60,61]$, with a minimum period of two weeks [52-54] and a maximum of two seasons [32]. In only $12 \%$ of the studies the design of the articles was longitudinal and experimental $[38,44,57,61]$, with the total research period between two to nine weeks, and in $32 \%$ the design was longitudinal and descriptive [22,26,30,32,35,39-42,52$55,60]$, with a minimum and maximum period of two weeks [52-54] to two seasons [32], respectively. In $18 \%$ of the articles the design was cross-sectional and experimental $[28,33,36,46,59,63,65-67]$, and in $38 \%$ of the articles the design was cross-sectional and descriptive $[2,21,23,24,27,31,37,45,47-51,56,58,62,64,68,69]$.

Figure 4 shows the temporal distribution of the instrumentsusedtomonitorsleep.Actigraphs, sleepdiaries and questionnaires were the most used instruments. It is noteworthy that the first study with polysomnography was in 2001 [64] and the first study with actigraphy was in 2014 [52]. The different instruments were used together in several studies, such as: Actigraphy and sleep diary $[2,21,27,30,36,38,44,46,51-54,57,60,61,67]$, actigraphy and questionnaires $[2,38,39,44,50,57,60]$, 

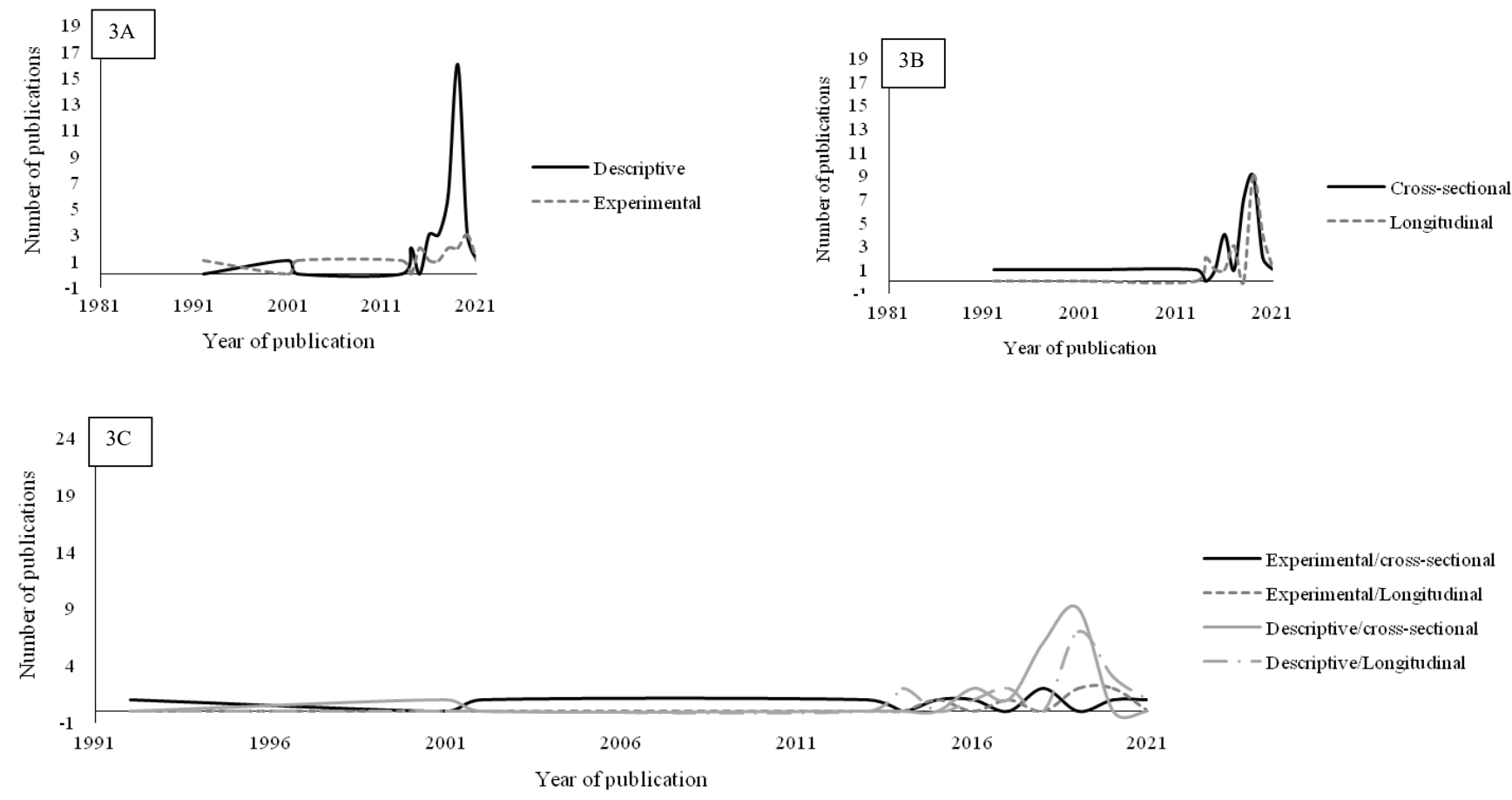

Figure 3: Temporal distribution of the articles regarding the type of study (3A), study time (3B), and study type and study time combined (3C).

\section{Used tools}

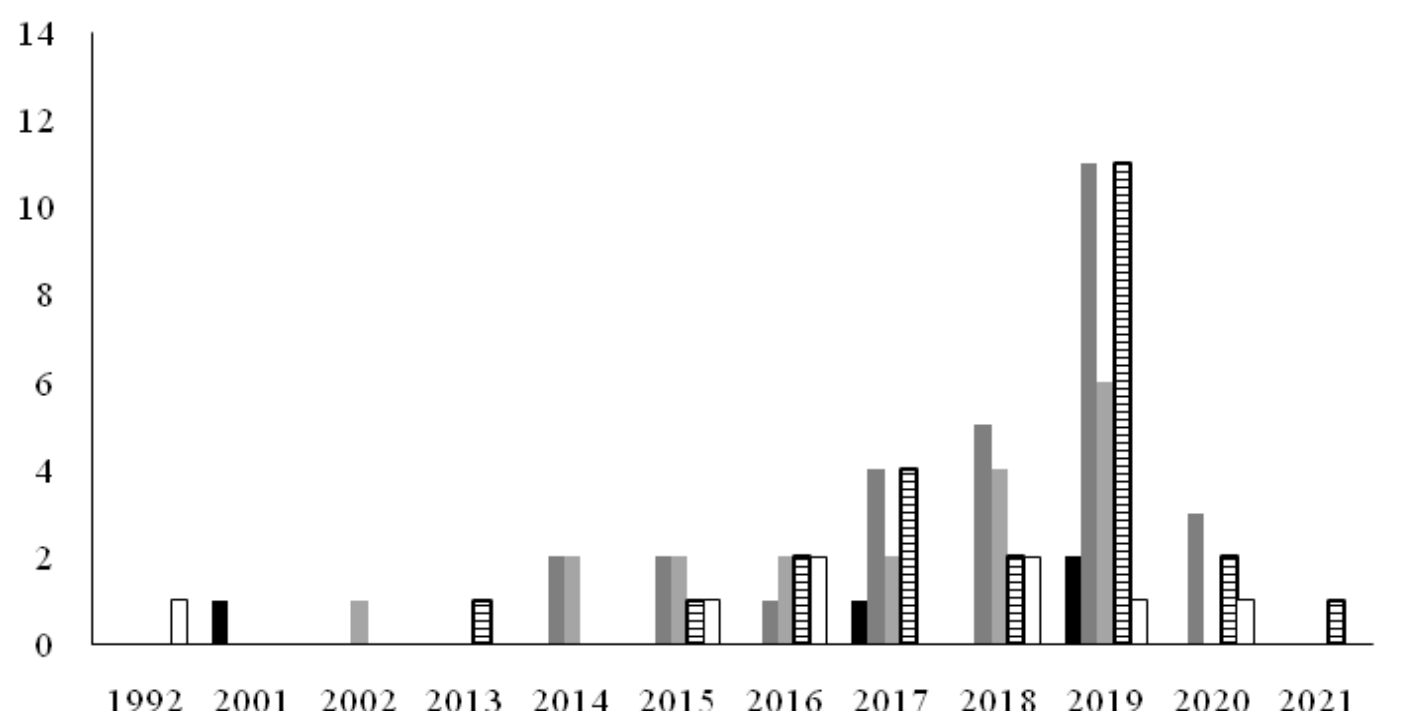

Figure 4: Temporal distribution of instruments used in articles on adult elite athlete sleep (1992-2021).

and questionnaires and polysomnography $[47,50]$. From 2015 onwards most studies used actigraphy to describe sleep. Philips Respironics actigraphs were the most used (Figure 5). The most used models were Actiwatch 2 $[21,22,29,44,46,57,60]$. Actical $[2,24,50,51]$, and the Aw$64[53,54]$, however, some articles did not describe the model used $[30,52,61,67]$. The second and third most used actigraphy brands were ActiGraph $[27,41,42,55,60]$ and Fatigue Science [26,36-39], respectively. Actigraphy was used for at least one day [50] and a maximum of 30 weeks [55]. Compumedics ${ }^{\circ}$ Polysomnography was the most used [47,50], while polysomnography's from Embla
Systems Inc. [23], and Oxford Medical Systems [64] also were present. In all articles that used polysomnography to describe sleep, the athletes were monitored for one night.

Eleven subjective instruments were utilized since 1994 (Figure 6). The sleep diary $[2,21,27,30,35,36,38,44,46,51$ $54,57,59-61,63,67]$ was the most used instrument, followed by the Pittsburgh Sleep Quality Index - PSQI$[31,35,38,44,45,49,50,57,68]$. The Epworth sleepiness scale $[2,31,38,45,47,49,51,57,62]$, the subjective wellness $[25,28,32,34,43,48,60,67]$, the self-report $[40,62,65]$, the interview $[45,69]$, the Karolinska Sleep 


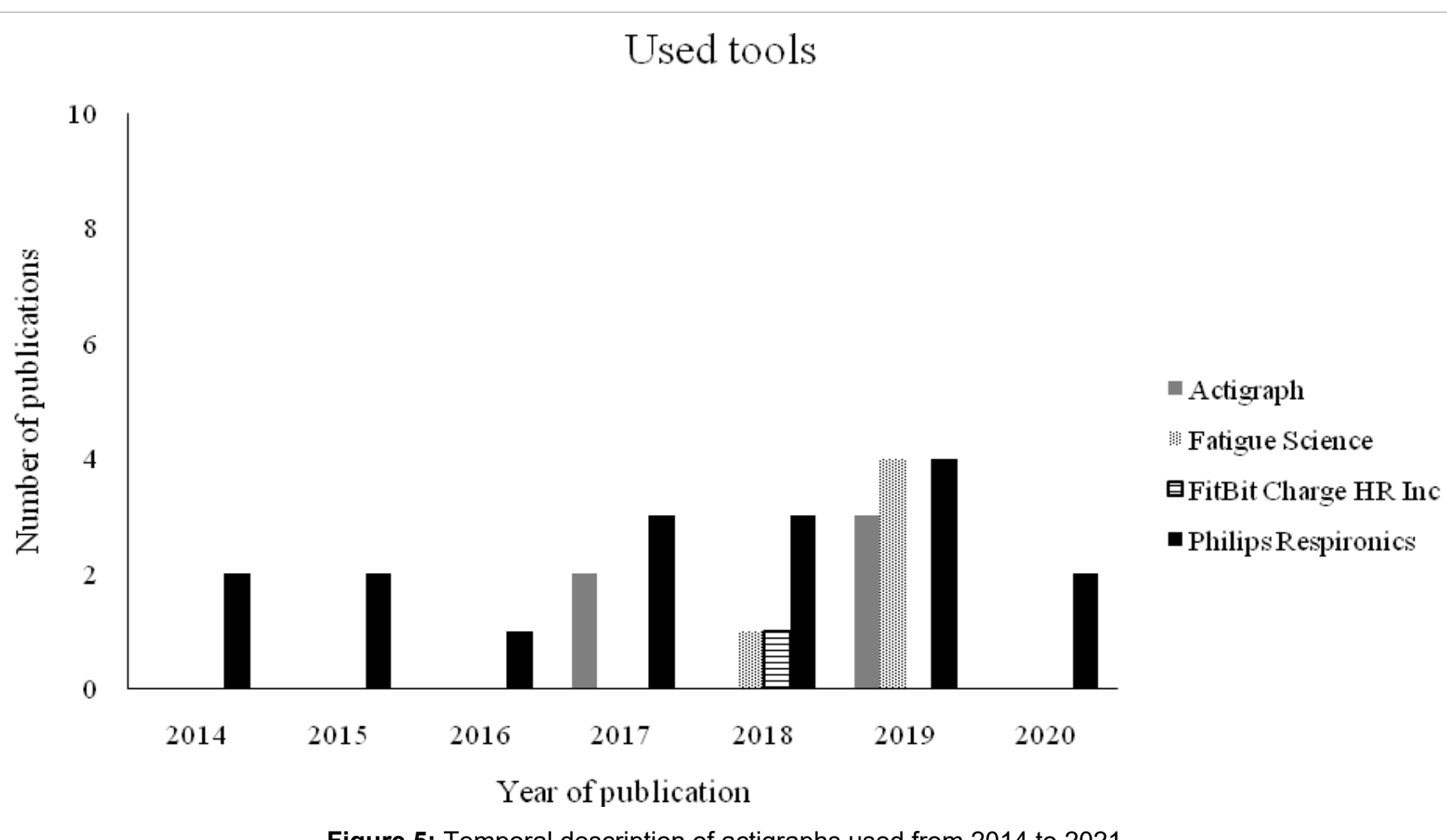

Figure 5: Temporal description of actigraphs used from 2014 to 2021.

\section{Subjective instruments used}

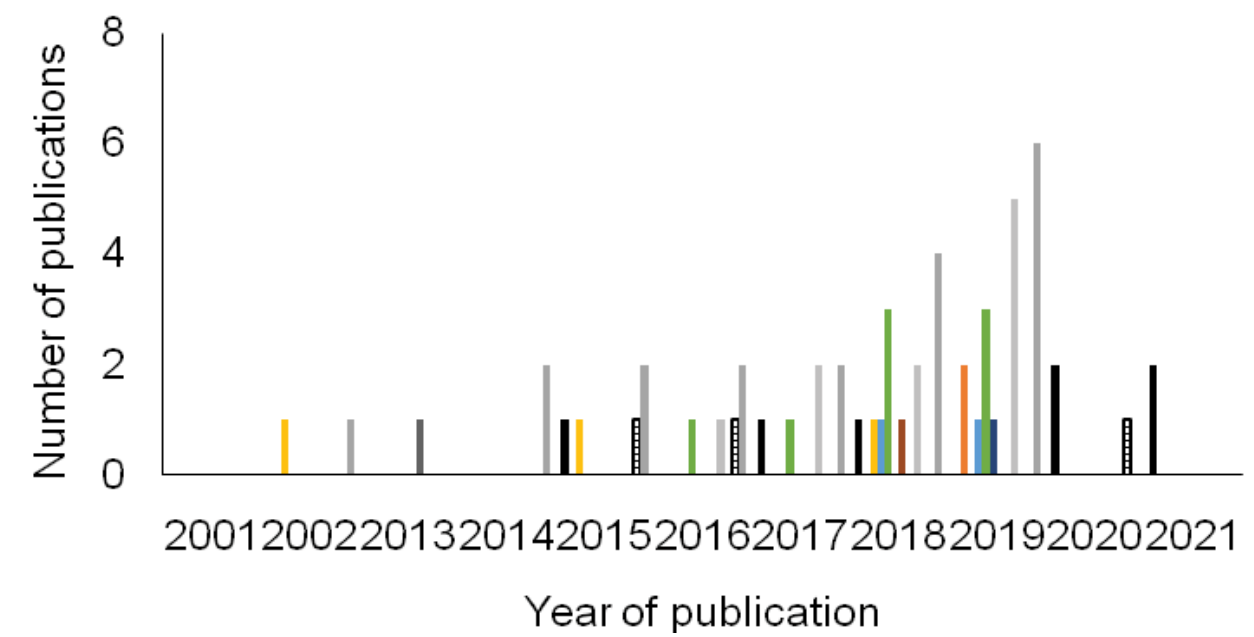

-Wellness

- $\mathrm{ASBQ}$

$\square$ Analog scale

- Interview

ESS

$\square|S|$

$\mathrm{KSQ}$

- LJLQ

- PSQI

Figure 6: Temporal description of the subjective instruments used from 1992 to 2021.

ASBQ: Athlete Sleep Behavior Questionnaire; ESS: Epworth sleepiness scale; ISI: Insomnia Severity Index, KSD: Karolinska Sleep Questionnaire; LJLQ: Liveerpool Jet-Lag Questionnaire; PSQI: Pittsburgh Sleep Quality Index; SSS: Stanford Sleepiness Scale.

Questionnaire [2], the Insomnia Severity Index -ISI[47], the Liverpool Jet-Lag Questionnaire -LJLQ- [66], and the Visual Analog Scale -AS- [2] were also used. It is noteworthy that there is only one questionnaire specific for the athlete population, the Athlete Sleep Behavior Questionnaire (ASBQ) [38,39].

\section{Discussion}

With the observation of the presented data, it can be affirmed that in no other historical moment the observation and monitoring of the elite adult athlete's sleep were so inserted in the scientific area. However, several methodological issues contribute to extensive diversity in information content. These questions are a challenge to systematize the information made available in the studies and expand the debate in the scientific world. It can be highlighted that the years 2018 and 2019 , with $52 \%$ of the total publications, were important to increase the number of publications on this topic.

The present review indicates a growth of studies around elite adult athlete sleep. In the last five years, there has been an increase in the number of publications. Between 2014 and 2020, 37 of the 50 articles were published. Interestingly, until the year 
2010, there were only three publications. Three facts are important to help understand this historical evolution. First, it is the effort of different organizations to expand the knowledge of the importance of sleep in the field of public health. The National Sleep Foundation [4] and the American Academy of Sleep Medicine [70] have published recommendations regarding the number of sleep hours, in addition to reinforcing the importance of sleep for health. The American Heart Association [71] published a statement on the importance of optimal sleep and its relationship to cardiometabolic diseases and urged health organizations to include evidencebased sleep recommendations for optimal health.

The second fact to be considered is the assertion of the importance of the athlete's recovery process to improve sports performance, with emphasis on the reviews by Kenttä and Hassmén [72], and Bishop, Jones [73]. Finally, the third fact is the inclusion of studies affirming the importance of sleep for athletes, both in the physical recovery process and for sports performance. Samuels [7] and Halson [74] were the pioneers to review this theme, with publications that indicated the importance of sleep for optimal physical performance $[75,76]$. Together, these three facts can help us understand this quantitative increase in the publication of articles about athlete sleep.

The results presented in this review point to an overall increase in the number of publications on athlete sleep. However, there is an inequality in the number of publications regarding the continental origin of the studies. For example, there is a concentration of publications in Oceania and a shortage of publications in America and Asia. This shortage is alarming and should be viewed with concern by researchers in these regions. Different geographic factors can affect the athlete's sleep, such as altitude, temperature, and the number of hours of sunshine [77-80]. And these factors are different on different continents. Since sleep can be affected by the geographic characteristics mentioned above, the generalization of research results for application in athletes from different areas of the world should be considered.

We observed that male athletes were more present in the studies in this review, either in number of studies with only male athletes or in the number of male athletes in general. Sports scientists avoid selecting only women as study volunteers due, in part, to methodological challenges and the complexity of reporting heterogeneous results in within- and betweenstudy comparisons [81]. It is known that the menstrual cycle can affect performance in some activities so much [82] as some sleep variables. Thus, future studies must include more elite adult female athletes in the sample, in addition to describing the menstrual cycle so that you can understand the heterogeneous results according to the observed menstrual phase.
Most studies used elite adult athletes with national performance, with $40 \%$ of articles with elite adult athletes at the international level. Rating an athlete's performance level is a difficult task, considering the difficulty in obtaining the information needed to rate them. Initially, it is important to understand the differences between exercisers and athletes [83], understand what an elite athlete is [84], and the degree of electiveness [13]. Studying the sample with elite athletes brings several challenges, such as the difficulty to select a homogeneous sample, low sample number, difficulty in randomization, and use of a control group, in addition to generalization of the results. On the other hand, samples with elite athletes allow studying individuals submitted to considerable stress (physical, emotional, and mental) and high levels of fitness [85]. Thus, the classification used in this article serves as an initial survey so that you can describe the articles with elite athletes and, in the future, compare the sleep of the highest-level elite athlete (e.g., Olympic champion) with elite athletes of other levels.

Regarding the sports present in the studies, soccer was the sport present in the largest number of articles in this review. Some factors can be considered for this result. Soccer is the most popular sport in the world, with approximately 400 million players in more than 208 countries [86]. In this way, the great popularity and financial interest can help to understand why soccer is the most researched sport. Other sports stood out due to the number of publications in which they were studied, such as rugby and Australian football. This can be explained by the fact that six of the seven institutions that research the most about athlete sleep belong to Oceania, where rugby is widespread $[87,88]$, as well as Australian football. On the other hand, some modalities were little observed, such as judo, weightlifting, and Mixed Martial Arts. Consequently, future studies may investigate the athlete's sleep in different modalities.

Most articles had a cross-sectional and descriptive design. Cross-sectional research is commonly used in the scientific area, presenting the advantages of collecting large amounts of data, for example, evaluating the sleep of dozens or hundreds of athletes. It is also a relatively quick study and one that can investigate numerous variables simultaneously. However, this type of study allows you to analyze the data in just one moment [89]. The longitudinal and descriptive design represents $32 \%$ of the investigated articles. The longitudinal study allows taking notes and detecting any changes that occur in the characteristics evaluated [90]. This type of design was widely used among the studies present in this review since many of them aimed to monitor the sleep of athletes during a certain period, whether in training or competition. The number of studies with a longitudinal and experimental design is still scarce. Thus, more studies with an experimental design that 
can verify changes in interventions or treatments that impact the athlete's sleep pattern or architecture are important for advancing research on the athlete's sleep. Interestingly, we can observe that in recent years there has been an increase in the number of publications of longitudinal and experimental articles. These study designs are responsible for a small part of the number of publications, but this increase recent increase in the number of publications can be considered due to the relevance of developing strategies that can improve the quantity and quality of sleep on athletes.

Regarding instruments to monitor sleep in elite adult athletes, actigraphy was the most used method. Actigraphy is a device that monitors movements for long periods, where movement scores are translated according to computerized algorithms. Since studies have reported the validation of actigraphy for use in sleep-wake cycle description studies [91], and from reviews and guidelines established for its use, especially for athletes, there was an increase in the number of publications using this instrument. There were only two studies with actigraphy before the year 2015. Previously, data were primarily collected through questionnaires, diaries, and polysomnography. The study of Sargent, Lastella [92], established guidelines for the interpretation and measurements of sleep by actigraphy in athletes, with the definition of the activity count threshold 80 to define wakefulness with the greater agreement, sensitivity, and specificity compared to other thresholds that may overestimate the duration and quality of this recovery period. In this study, 04 times below/ above the established threshold were used to define the beginning/end of sleep. The fact that actigraphy is the most used method may be due to its advantages, such as its low cost compared to polysomnography, the possibility of using it in larger numbers of athletes and time intervals simultaneously, in addition to greater ecological validity. However, actigraphy does not present neurophysiological characteristics of sleep [93]. The company that owns the actigraphy most used in the research was validated in the 2000s [94]. Companies with five citations had their validations in 2000 [95] and 2011 [96]. Another point that reinforces the use of the Philips Respironics model is the fact that it is the only model in which there is evidence about its specific validity for elite athletes [92]. To date, there is still no evidence on the validation of other models and brands of actigraphs for competitors. Due to the athlete's training routine and competitions, numerous specifics for this population are reported [8]. From this perspective, the instruments used in this population must be adapted (accelerometer calibration, software settings, among other adaptations) to the reality of athletes, so that errors are reduced about equipment not calibrated for this purpose.

The other two most used instruments, such as the sleep diary and PSQI, are faster to obtain data, however, they are subjective methods and present a greater possibility of error when compared to instruments such as polysomnography and actigraphy. In the study of Samuels, James [97], it was reported that the PSQI underestimates the quality of sleep in athletes, that is, it decreases the quality of sleep through this tool, in addition to showing low agreement for this population. Therefore, the development and use of specific and validated tools for athletes, the ASBQ, is of fundamental importance. The ASBQ is a questionnaire that analyzes the different behaviors related to sleep hygiene and circadian synchronization in specific situations of the sport context [39].

Another interesting point is that few studies used specific questionnaires for the athlete population. Despite its wide use in studies with athletes, the PSQI is not validated and specific about the population, like the ASBQ. However, in the studies presented, the ASBQ was used in only two studies [38,39]. As this instrument was presented and validated in 2018, we suggest greater use of this instrument in studies of elite athletes. In addition, we also suggest the cross-cultural adaptation of these questionnaires, as they are only available in English, Portuguese, and Turkish $[98,99]$. An increase in the use of these questionnaires is expected in the coming years, as they were recently developed.

This study has some limitations, such as the use of articles only in English, which leads to non-selection of articles published in other languages; the use of only elite adult athletes disregarded modalities in which the peak of performance occurs before the age of 18 , such as gymnastics. The exclusion of paralympic athletes or adapted modalities as eligibility criteria for this article may reduce the extrapolation of information for these athletes. Besides, we analyzed only studies with elite adult athletes. The age of peak performance can be different according to the modality or event [100]. So, some studies can be analyzed the sleep pattern in younger elite athletes, however, this sample was not our sample of analyzes.

Thus, it is concluded that in no other historical moment the sleep of the elite adult athlete was so inserted in the scientific area. There is a historicalscientific movement for the use of actigraphy in the description of the sleep-wake cycle, on the other hand, the use of specific instruments for the athlete population is still limited. Historically, most publications are made up of descriptive studies with elite adult male athletes from soccer and rugby. Thus, elite adult athlete sleep research is an expanding area in sports science, and factors such as elite adult athlete's gender and modality, as well as the publication's instruments and geographic location, will contribute to filling the knowledge gaps in this theme. With this, it is expected an advance in the study about the athlete's sleep for greater dissemination of information based on scientific evidence to encourage 
the awareness of athletes and the technical committee of the importance of sleep for this population.

\section{Disclosure of Interest}

The authors report no conflict of interest.

\section{Funding}

No financial organization was involved in the material discussed in the manuscript.

\section{Ethical Approval and Consent to Participate}

Not applicable.

\section{The Authors' Contributions}

ACS, LAF, ASA, JPPR, DAB, AS, and MTM all contributed to the paper. ACS designed the search strategy. ACS, LAF, and ASA performed the study selection and composed the manuscript. All authors critically revised it and approved the final version of the article.

\section{References}

1. Taylor SR, Rogers GG, Driver HS (1997) Effects of training volume on sleep, psychological, and selected physiological profiles of elite female swimmers. Med Sci Sports Exer 29 688-693.

2. Juliff LE, Peiffer JJ, Halson SL (2018) Night games and sleep: Physiological, neuroendocrine, and psychometric mechanisms. Int J Sports Physiol Perform 13: 867-873.

3. Lastella M, Lovell GP, Sargent C (2014) Athletes' precompetitive sleep behaviour and its relationship with subsequent precompetitive mood and performance. Eur $\mathrm{J}$ Sport Sci 14: S123-S130.

4. Hirshkowitz M, Whiton K, Albert SM, Alessi C, Bruni O, et al. (2015) National Sleep Foundation's sleep time duration recommendations: Methodology and results summary. Sleep Health 1: 40-43.

5. Bird SP (2013) Sleep, recovery, and athletic performance: a brief review and recommendations. Strength Cond J 35: 43-47.

6. Fallon KE (2007) Blood tests in tired elite athletes: expectations of athletes, coaches and sport science/sports medicine staff. Br J Sports Med 41: 41-44.

7. Samuels C (2008) Sleep, recovery, and performance: The new frontier in high-performance athletics. Neurol Clin 26 169-180.

8. Roberts SSH, Teo W-P, Warmington SA (2019) Effects of training and competition on the sleep of elite athletes: $A$ systematic review and meta-analysis. Br J Sports Med 53: 513-522.

9. Silva M, Paiva T, Silva H-H (2019) The elite athlete as a special risk traveler and the jet lag's effect: lessons learned from the past and how to be prepared for the next Olympic Games 2020 Tokyo. J Sport Med Phys Fit 59: 1420-1429.

10. Reilly T, Atkinson G, Edwards B, Waterhouse J, Åkerstedt T, et al. (2007) Coping with jet-lag: a position statement for the European College of Sport Science. Eur J Sport Sci 7: $1-7$.

11. Lastella M, Memon AR, Vincent GE (2020) Global research output on sleep research in athletes from 1966 to 2019: a bibliometric analysis. Clocks \& Sleep 2: 99-119.
12. Araújo C, Scharhag J (2016) Athlete: A working definition for medical and health sciences research. Scand J Med Sci Spor 26: 4-7.

13. Swann C, Moran A, Piggott D (2015) Defining elite athletes: Issues in the study of expert performance in sport psychology. Psychol Sport Exer 16: 3-14.

14. Williams A, Day S, Stebbings G, Erskine R (2017) What does 'elite'mean in sport and why does it matter. Sport Exer Scie 51.

15. Moher D, Liberati A, Tetzlaff J, Altman DG (2010) Preferred reporting items for systematic reviews and meta-analyses: The PRISMA statement. Int J Surg 8: 336-341.

16. Lamont-Mills A, Christensen SA (2006) Athletic identity and its relationship to sport participation levels. J Sci Med Sport 9: $472-478$.

17. Tran G, Smith TO, Grice A, Kingsbury SR, McCrory P, et al. (2016) Does sports participation (including level of performance and previous injury) increase risk of osteoarthritis? A systematic review and meta-analysis. $\mathrm{Br} \mathrm{J}$ Sports Med 50: 1459-1466.

18. Kooistra B, Dijkman B, Einhorn TA, Bhandari M (2009) How to design a good case series. JBJS 91: 21-26.

19. Caruana EJ, Roman M, Hernández-Sánchez J, Solli $P$ (2015) Longitudinal studies. J Thorac Dis 7: E537.

20. de Leeuw E, Hox JJ, Dillman D (2008) International handbook of survey methodology. New York: Taylor \& Francis.

21. Vitale JA, Banfi G, Galbiati A, Ferini-Strambi L, La Torre A (2019) Effect of a night game on actigraphy-based sleep quality and perceived recovery in top-level volleyball athletes. Int J Sports Physiol Perform 14: 265-269.

22. Silva A, Narciso FV, Soalheiro I, Viegas F, Freitas LSN, et al. (2020) Poor sleep quality's association with soccer injuries: preliminary data. Int J Sports Physiol Perform 15: 671-676.

23. Silva A, Narciso FV, Rosa JPP, Rodrigues DF, Cruz AÂ DS, et al. (2019) Gender differences in sleep patterns and sleep complaints of elite athletes. Sleep Sci 12: 242-248.

24. Serpell BG, Horgan BG, Colomer CME, Field B, Halson SL, et al. (2019) Sleep and salivary testosterone and cortisol during a short preseason camp: a study in professional rugby union. Int J Sports Physiol Perform 14: 796-804.

25. Ryan S, Crowcroft S, Kempton T, Coutts AJ (2021) Associations between refined athlete monitoring measures and individual match performance in professional Australian football. Sci Med Football 5: 216-224.

26. Peacock CA, Mena M, Sanders GJ (2018) Sleep data, physical performance, and injuries in preparation for professional mixed martial arts. Sports (Basel, Switzerland) 7.

27. Nédélec M, Dawson B, Dupont G (2019) Influence of night soccer matches on sleep in elite players. J Strength Cond Res 33: 174-179.

28. Moreira A, da Silva Machado DG, Moscaleski L, Bikson M, Unal G, et al. (2021) Effect of tDCS on well-being and autonomic function in professional male players after official soccer matches. Physiol Behav 233: 113351.

29. Mello MTd, Simim MAdM, Narciso FV, Rosa JPP, Rodrigues DF, et al. (2020) Duration and quality of sleep in sprint and recovery performances among elite swimmers. Rev Bras Med Esporte 26: 126-129. 
30. Lastella M, Roach GD, Sargent C (2019) Travel fatigue and sleep/wake behaviors of professional soccer players during international competition. Sleep Health 5: 141-147.

31. Khalladi K, Farooq A, Souissi S, Herrera CP, Chamari K, et al. (2019) Inter-relationship between sleep quality, insomnia and sleep disorders in professional soccer players. BMJ Open Sport Exercise Med 5: e000498.

32. Howle K, Waterson A, Duffield R (2019) Recovery profiles following single and multiple matches per week in professional football. Eur J Sport Sci 19: 1303-1311.

33. Hoshikawa M, Uchida S, Dohi M (2020) Intervention for reducing sleep disturbances after a 12-time zone transition. J Strength Cond Res 34: 1803-1807.

34. Grainger A, Comfort P, Heffernan S (2020) No effect of partial-body cryotherapy on restoration of countermovement jump or well-being performance in elite Rugby Union players during the competitive phase of the season. Int J Sports Physiol Perform 5: 98-104.

35. Fitzgerald D, Beckmans C, Joyce D, Mills K (2019) The influence of sleep and training load on illness in nationally competitive male Australian Football athletes: A cohort study over one season. J Sci Med Sport 22: 130-134.

36. Dunican IC, Higgins CC, Jones MJ, Clarke MW, Murray K, et al. (2018) Caffeine use in a Super Rugby game and its relationship to post-game sleep. Eur J Sport Sci 18: 513523

37. Dunican IC, Higgin CC, Murray K, Jones MJ, Dawson B, et al. (2019) Sleep patterns and alertness in an elite super rugby team during a game week. J Hum Kinet 67: 111-121.

38. Driller MW, Lastella M, Sharp AP (2019) Individualized sleep education improves subjective and objective sleep indices in elite cricket athletes: A pilot study. J Sports Sci 37: 2021-2025.

39. Driller M, Cupples B (2019) Sleep prior to and following competition in professional rugby league athletes. Sci Med Football 3: 57-62.

40. Crewther BT, Potts N, Kilduff LP, Drawer S, Cook CJ (2020) Performance indicators during international rugby union matches are influenced by a combination of physiological and contextual variables. J Sci Med Sport 23: 396-402.

41. Costa JA, Brito J, Nakamura FY, Oliveira EM, Costa OP, et al. (2019) Does night training Load affect sleep patterns and nocturnal cardiac autonomic activity in high-level female soccer players? Int J Sports Physiol Perform 14: 779-787.

42. Costa JA, Brito J, Nakamura FY, Figueiredo P, Oliveira E, et al. (2019) Sleep patterns and nocturnal cardiac autonomic activity in female athletes are affected by the timing of exercise and match location. Chronobiol Int 36: 360-373.

43. Clemente FM, Bredt SdGT, Praça GM, Duarte E, Mendes B (2020) Relationships between wellness status and perceived training load on daily and weekly bases over basketball season. Kinesiology 52: 151-156.

44. Vitale JA, Devetag F, Colnago S, La Torre A (2019) Effect of mattress on actigraphy-based sleep quality and perceived recovery in top-level athletes: A randomized, double-blind, controlled trial. Biol Rhythm Res 50: 689-702.

45. Hoshikawa M, Uchida S, Hirano Y (2018) A subjective assessment of the prevalence and factors associated with poor sleep quality amongst elite Japanese athletes. Sports Med Open 4: 10.

46. Rosa JPP, Silva A, Rodrigues DF, Simim MA, Narciso FV et al. (2018) Effect of bright light therapy on delayed sleep/ wake cycle and reaction time of athletes participating in the Rio 2016 Olympic Games. Chronobiol Int 35: 1095-1103.
47. Dunican IC, Walsh J, Higgins CC, Jones MJ, Maddison $\mathrm{K}$, et al. (2019) Prevalence of sleep disorders and sleep problems in an elite super rugby union team. J Sports Sci 37: 950-957.

48. Costa JA, Brito J, Nakamura FY, Oliveira EM, Rebelo AN (2018) Effects of late-night training on "slow-wave sleep episode" and hour-by-hour-derived nocturnal cardiac autonomic activity in female soccer players. Int J Sports Physiol Perform 13: 638-644.

49. Drew M, Vlahovich N, Hughes D, Appaneal R, Burke LM, et al. (2018) Prevalence of illness, poor mental health and sleep quality and low energy availability prior to the 2016 Summer Olympic Games. Br J Sports Med 52: 47-53.

50. Fuller KL, Juliff L, Gore CJ, Peiffer JJ, Halson SL (2017) Software thresholds alter the bias of actigraphy for monitoring sleep in team-sport athletes. J Sci Med Sport 20: $756-760$.

51. Juliff LE, Halson SL, Hebert JJ, Forsyth PL, Peiffer JJ (2018) Longer sleep durations are positively associated with finishing place during a national multiday netball competition. J Strength Cond Res 32: 189-194.

52. Sargent C, Halson SL, Roach GD (2014) Sleep or swim? Early-morning training severely restricts the amount of sleep obtained by elite swimmers. Eur J Sport Sci 14 Suppl 1: S310-S315

53. Sargent C, Lastella M, Halson SL, Roach GD (2014) The impact of training schedules on the sleep and fatigue of elite athletes. Chronobiol Int 31: 1160-1168.

54. Sargent C, Roach GD (2016) Sleep duration is reduced in elite athletes following night-time competition. Chronobiol Int 33: 667-670.

55. Staunton C, Gordon B, Custovic E, Stanger J, Kingsley M (2017) Sleep patterns and match performance in elite Australian basketball athletes. J Sci Med Sport 20: 786-789.

56. Thornton HR, Delaney JA, Duthie GM, Dascombe BJ (2018) Effects of preseason training on the sleep characteristics of professional rugby league players. Int J Sports Physiol Perform 13: 176-182.

57. Van Ryswyk E, Weeks R, Bandick L, O'Keefe M, Vakulin A, et al. (2017) A novel sleep optimisation programme to improve athletes' well-being and performance. Eur J Sport Sci 17: 144-151.

58. Eagles A, McLellan C, Hing W, Carloss N, Lovell D (2016) Changes in sleep quantity and efficiency in professional rugby union players during home based training and matchplay. J Sport Med Phys Fit 56: 565-571.

59. Fowler PM, Duffield R, Lu D, Hickmans JA, Scott TJ (2016) Effects of long-haul transmeridian travel on subjective jetlag and self-reported sleep and upper respiratory symptoms in professional rugby league players. Int J Sports Physiol Perform 11: 876-884.

60. Pitchford NW, Robertson SJ, Sargent C, Cordy J, Bishop DJ, et al. (2017) Sleep quality but not quantity altered with a change in training environment in elite Australian rules football players. Int J Sports Physiol Perform 12: 75-80.

61. Lastella M, Roach GD, Halson SL, Martin DT, West NP, et al. (2015) The impact of a simulated grand tour on sleep, mood, and well-being of competitive cyclists. J Sport Med Phys Fit 55: 1555-1564.

62. Lastella M, Roach GD, Halson SL, Sargent C (2016) The chronotype of elite athletes. J Hum Kinet 54: 219-225.

63. Cardinali DP, Bortman GP, Liotta G, Pérez Lloret S, Albornoz LE, et al. (2002) A multifactorial approach employing melatonin to accelerate resynchronization of sleep-wake 
cycle after a 12 time-zone westerly transmeridian flight in elite soccer athletes. J Pineal Res 32: 41-46.

64. Netzer NC, Kristo D, Steinle H, Lehmann M, Strohl KP (2001) REM sleep and catecholamine excretion: A study in elite athletes. Eur J Appl Physiol 84: 521-526.

65. Tafti M, Besset A, Billiard M (1992) Effects of zopiclone on subjective evaluation of sleep and daytime alertness and on psychomotor and physical performance tests in athletes. Prog Neuropsychopharmacol Biol Psychiatry 16: 55-63.

66. Thompson A, Batterham AM, Jones H, Gregson W, Scott D, et al. (2013) The practicality and effectiveness of supplementary bright light for reducing jet-lag in elite female athletes. Int J Sports Med 34: 582-589.

67. Fowler P, Duffield R, Howle K, Waterson A, Vaile J (2015) Effects of northbound long-haul international air travel on sleep quantity and subjective jet lag and wellness in professional Australian soccer players. Int J Sports Physiol Perform 10: 648-654.

68. Bender A, Van Dongen H (2019) Sleep quality and chronotype differences between elite athletes and nonathlete ontrols. Clocks Sleep 1: 3-12.

69. Yasuda J, Yoshizaki T, Yamamoto K, Yoshino M, Ota M, et al. (2019) Association of frequency of milk or dairy product consumption with subjective sleep quality during training periods in Japanese elite athletes: A cross-sectional study. J Nutr Sci Vitaminol (Tokyo) 65: 177-183.

70. Watson NF, Badr MS, Belenky G, Bliwise DL, Buxton OM, et al. (2015) Recommended amount of sleep for a healthy adult: $A$ joint consensus statement of the American Academy of Sleep Medicine and Sleep Research Society. Sleep 11: 591-592.

71. St-Onge M-P, Grandner MA, Brown D, Conroy MB, JeanLouis G, et al. (2016) Sleep duration and quality: Impact on lifestyle behaviors and cardiometabolic health: A scientific statement from the American Heart Association. Circulation 134: e367-e386.

72. Kenttä G, Hassmén P (1998) Overtraining and recovery. Sports Med 26: 1-16.

73. Bishop PA, Jones E, Woods AK (2008) Recovery from training: A brief review. J Strength Cond Res 22: 1015-1024.

74. Halson SL (2008) Nutrition, sleep and recovery. Eur J Sport Sci 8: 119-126.

75. Halson SL (2013) Recovery techniques for athletes. Sports Scie Ex 26: 1-6

76. Halson SL (2014) Sleep in elite athletes and nutritional interventions to enhance sleep. Sports Med 44: 13-23.

77. Buguet A, Hankourao O, Gati R (1990) Self-estimates of sleep in African students in a dry tropical climate. J Environ Psychol 10: 363-369.

78. Friborg O, Rosenvinge JH, Wynn R, Gradisar M (2014) Sleep timing, chronotype, mood, and behavior at an Arctic latitude (69 N). Sleep Med 15: 798-807.

79. Kohsaka M, Fukuda N, Honma K, Honma S, Morita N (1992) Seasonality in human sleep. Experientia 48: 231-233.

80. Sivertsen B, Øverland S, Krokstad S, Mykletun A (2011) Seasonal variations in sleep problems at latitude $63-65$ in Norway: the Nord-Trøndelag Health Study, 1995-1997. Am J Epidemiol 174: 147-153.

81. Elliott-Sale KJ, Minahan CL, de Jonge XAJ, Ackerman KE, Sipilä S, et al. (2021) Methodological considerations for studies in sport and exercise science with women as participants: A working guide for standards of practice for research on women. Sports Med 51: 843-861.
82. McNulty KL, Elliott-Sale KJ, Dolan E, Swinton PA, Ansdell $P$, et al. (2020) The effects of menstrual cycle phase on exercise performance in eumenorrheic women: a systematic review and meta-analysis. Sports Med 50: 1813-1827.

83. McKinney J, Velghe J, Fee J, Isserow S, Drezner JA (2019) Defining athletes and exercisers. Am J Cardiol 123: 532535.

84. Lorenz DS, Reiman MP, Lehecka B, Naylor A (2013) What performance characteristics determine elite versus nonelite athletes in the same sport? Sports Health 5: 542-547.

85. Sands WA, McNeal JR, Stone MH (2005) Plaudits and pitfalls in studying elite athletes. Percept Mot Skills 100: 2224.

86. Coelho MGR, Amorim JGBd, Almeida VMCd (2019) Sports mega-event sponsorship: The impact of FIFA reputation and world cup image on sponsor brand equity. BAR-Braz Adm Rev 16: e180071.

87. Horton P (2014) Pacific Islanders in professional rugby football: Bodies, minds and cultural continuities. Asia Pac J Sport Soc Sci 3: 222-235.

88. Saw R, Finch CF, Samra D, Baquie P, Cardoso T, et al. (2018) Injuries in Australian rules football: An overview of injury rates, patterns, and mechanisms across all levels of play. Sports Health 10: 208-216.

89. Zangirolami-Raimundo J, Echeimberg JDO, Leone C (2018) Tópicos de metodologia de pesquisa: Estudos de corte transversal. J Hum Growth Dev 28: 356-360.

90. loannidis JP, Munafo MR, Fusar-Poli P, Nosek BA, David SP (2014) Publication and other reporting biases in cognitive sciences: detection, prevalence, and prevention. Trends Cogn Sci 18: 235-241.

91. Sadeh A (2011) The role and validity of actigraphy in sleep medicine: an update. Sleep Medi Rev 15: 259-267.

92. Sargent C, Lastella M, Halson SL, Roach GD (2016) The validity of activity monitors for measuring sleep in elite athletes. J Sci Med Sport 19: 848-853.

93. Halson SL (2019) Sleep monitoring in athletes: Motivation, methods, miscalculations and why it matters. Sports Med 49: $1487-1497$

94. Kushida CA, Chang A, Gadkary C, Guilleminault C, Carrillo O, et al. (2001) Comparison of actigraphic, polysomnographic, and subjective assessment of sleep parameters in sleepdisordered patients. Sleep Med 2: 389-396.

95. Russell C, Caldwell J, Arand D, Myers L, Wubbels P, et al. (2000) Validation of the fatigue science readiband actigraph and associated sleep/wake classification algorithms.

96. Mori K, Mitsuki F, Nishi C, Yoshida T, Kawasaki A, et al. (2011) Usefulness of a Tri-Axis accelerometer for sleepwake scoring. World sleep meeting.

97. Samuels C, James L, Lawson D, Meeuwisse W (2016) The Athlete Sleep Screening Questionnaire: a new tool for assessing and managing sleep in elite athletes. $\mathrm{Br} \mathrm{J}$ Sports Med 50: 418-422.

98. Darendeli A, Diker G, Çınar Z (2019) Athlete sleep behavior questionnaire-Turkish version: Study of validity and reliability. J Turk Sleep Med 6: 43-48.

99. Facundo LA, Albuquerque M, Esteves A, Driller M, Grade I, et al. (2021) Cross-cultural adaptation of the Brazilian version of the athlete sleep behavior questionnaire. Sleep Sci.

100. Allen SV, Hopkins WG (2015) Age of peak competitive performance of elite athletes: A systematic review. Sports Med 45: 1431-1441. 